\title{
Influence of aprepitant on the pharmacodynamics and pharmacokinetics of gliclazide in rats and rabbits
}

\author{
Raghunandan Reddy Kura $^{1}$, Eswar Kumar Kilari ${ }^{1}$, Mastan Shaik ${ }^{\text {Corresp. } 2}$ \\ 1 Pharmacology Division, Andhra University College of Pharmaceutical Sciences, Andhra University, Visakhapatnam, Andhra Pradesh, India \\ 2 Medical Services, Troikaa Pharmaceuticals Ltd, Ahmedabad, Gujarat, India \\ Corresponding Author: Mastan Shaik \\ Email address: shkmastan@gmail.com
}

Background: Concomitant drug administration is a general phenomenon in the patients with chronic diseases such as diabetes mellitus. Among the currently available oral antidiabetic drugs, gliclazide is a commonly prescribed drug considering its multiple benefits in diabetic patients. Aprepitant is a commonly prescribed antiemetic drug which is mainly metabolized by CYP3A4, reported to have modest inductive and inhibitory effects on CYP2C9 and CYP3A4, respectively. Since gliclazide is metabolized by CYP2C9 (major) and CYP3A4 (minor), it is very difficult to predict the influence of aprepitant and its metabolic interaction with gliclazide. Considering the complexity associated with the combination of aprepitant and gliclazide, this study was designed to evaluate the influence of aprepitant on the pharmacodynamics (PD) and pharmacokinetics (PK) of gliclazide in animal models. Methods: The PD interaction studies were conducted in both rodent (normal and alloxan-induced diabetic rats) and non-rodent (rabbits) animal models $(n=6)$ while the PK interaction study was conducted in normal rabbits $(n=6)$. An extrapolated human therapeutic oral dose of gliclazide, aprepitant and their combination were administered to rats and rabbits with 7 days washout between each treatment. For the multiple-dose interaction study, the same groups were administered with an interacting drug (aprepitant) for 7 days and then the combination of aprepitant and gliclazide on $8^{\text {th }}$ day. From the collected animal blood samples, blood glucose (by Glucose-

Oxidase/Peroxidase method), insulin (by ELISA method) and gliclazide concentration levels (by HPLC method) were determined. Non-compartmental PK analysis was conducted by Phoenix WinNonlin software to determine the PK parameters of gliclazide. Statistical analysis was performed by student's paired t-test. Results: The pharmacodynamic activity (blood glucose reduction and insulin levels) of gliclazide was significantly $(p<0.05)$ influenced by aprepitant in normal and diabetic condition without any convulsions in animals. There was a significant $(p<0.05)$ increase in concentration levels and Area Under the Curve of gliclazide while significant $(p<0.05)$ decrease in clearance levels of gliclazide 
in rabbits. The PK interaction with gliclazide is relatively more with the multiple dose treatment of aprepitant over single dose treatment. Conclusion: In combination, aprepitant significantly influenced the pharmacodynamic activity of gliclazide in animal models. Considering this, care should be taken when this combination is prescribed for the clinical benefit in diabetic patients. 


\section{Influence of aprepitant on the pharmacodynamics and pharmacokinetics of 2 gliclazide in rats and rabbits}

3

4 Raghunandan Reddy Kura ${ }^{1}$, Eswar Kumar Kilari ${ }^{1}$, Mastan Shaik ${ }^{2 *}$

5

6 1Pharmacology Division, Andhra University College of Pharmaceutical Sciences, Andhra

7 University, Visakhapatnam, Andhra Pradesh, India

$8 \quad{ }^{2}$ Medical Services, Troikaa Pharmaceuticals Ltd., Ahmedabad, Gujarat, India

$18 *$ Correspondence:

19 Mastan Shaik, PhD

20 Assistant General Manager - Medical Services

21 Troikaa Pharmaceuticals Ltd, Bodakdev, Ahmedabad-380059, India

22 Phone: $+91-7032384747$

23 Email:shkmastan@gmail.com; mastanshaik@troikaapharma.com 


\section{ABSTRACT}

Background: Concomitant drug administration is a general phenomenon in the patients with chronic diseases such as diabetes mellitus. Among the currently available oral antidiabetic drugs, gliclazide is a commonly prescribed drug considering its multiple benefits in diabetic patients. Aprepitant is a commonly prescribed antiemetic drug which is mainly metabolized by CYP3A4, reported to have modest inductive and inhibitory effects on CYP2C9 and CYP3A4, respectively. Since gliclazide is metabolized by CYP2C9 (major) and CYP3A4 (minor), it is very difficult to predict the influence of aprepitant and its metabolic interaction with gliclazide. Considering the complexity associated with the combination of aprepitant and gliclazide, this study was designed to evaluate the influence of aprepitant on the pharmacodynamics (PD) and pharmacokinetics (PK) of gliclazide in animal models.

Methods: The PD interaction studies were conducted in both rodent (normal and alloxaninduced diabetic rats) and non-rodent (rabbits) animal models $(n=6)$ while the PK interaction study was conducted in normal rabbits $(n=6)$. An extrapolated human therapeutic oral dose of gliclazide, aprepitant and their combination were administered to rats and rabbits with 7 days washout between each treatment. For the multiple-dose interaction study, the same groups were administered with an interacting drug (aprepitant) for 7 days and then the combination of aprepitant and gliclazide on $8^{\text {th }}$ day. From the collected animal blood samples, blood glucose (by Glucose-Oxidase/Peroxidase method), insulin (by ELISA method) and gliclazide concentration levels (by HPLC method) were determined. Non-compartmental PK analysis was conducted by Phoenix WinNonlin software to determine the PK parameters of gliclazide. Statistical analysis was performed by student's paired t-test. 
48 Results: The pharmacodynamic activity (blood glucose reduction and insulin levels) of 49 gliclazide was significantly $(\mathrm{p}<0.05)$ influenced by aprepitant in normal and diabetic condition 50 without any convulsions in animals. There was a significant $(\mathrm{p}<0.05)$ increase in concentration 51 levels and Area Under the Curve of gliclazide while significant $(\mathrm{p}<0.05)$ decrease in clearance 52 levels of gliclazide in rabbits. The PK interaction with gliclazide is relatively more with the 53 multiple dose treatment of aprepitant over single dose treatment.

54 Conclusion: In combination, aprepitant significantly influenced the pharmacodynamic activity 55 of gliclazide in animal models. Considering this, care should be taken when this combination is 56 prescribed for the clinical benefit in diabetic patients. 


\section{INTRODUCTION}

Concomitant drug administration is a general phenomenon in the patients with chronic diseases such as diabetes mellitus. Despite the several benefits with concomitant drug administration, it is generally associated with increased risks of medication non-adherence, adverse drug reactions/events, and toxicity due to potential drug interactions (Peron, Ogbonna \& Donohoe, 2015). Monitoring and minimizing the risk of drug-drug interactions (either pharmacodynamic or pharmacokinetic) is a common goal in drug therapy while dealing with chronic diseases (Curtis, 2006). Diabetes mellitus is among the most prevalent and morbid chronic diseases which can adversely influence the health of millions of population worldwide (Julie \& John, 2017).

The prevalence of diabetes mellitus has been dramatically increased from 2005 to 2015 by 30.6\% (Global Burden of Disease Study, 2015). In high risk individuals, the overall prevalence of pre- and post-operative nausea and vomiting is in the range of 30 to $80 \%$ (Bergese et al., 2012). Among the currently available oral antidiabetic drugs, gliclazide is a commonly prescribed drug considering its multiple benefits (relatively low incidence of hypoglycemia, antioxidant activity and cardiovascular benefits) in diabetic patients (Fava et al., 2002; O'Brien et al., 2000; Schernthaner, 2003; Ziegler \& Drouin, 1994). Aprepitant is a potent, selective and brain-penetrant non-peptide neurokinin-1 (NK1)-receptor antagonist, widely used for the prevention of chemotherapy induced nausea and vomiting (Anna et al., 2017). Aprepitant is mainly metabolized by CYP3A4 and reported to have modest inductive and inhibitory effects on CYP2C9 and CYP3A4, respectively (Anna et al., 2017; Shadle et al., 2004).

There is a high propensity for the concomitant use of aprepitant and gliclazide in diabetic patients due to (a) high prevalence of diabetes mellitus and nausea/vomiting, (b) the recent trend to recommend aprepitant for the management of refractory diabetic gastroparesis in diabetic 
82 patients (Chong \& Dhatariya, 2009; Fountoulakis et al., 2017). Since gliclazide is metabolized

83 (Mastan \& Kumar, 2009; Satyanarayana \& Kumar, 2006) by CYP2C9 (major) and CYP3A4

84 (minor), it is very difficult to predict the influence of aprepitant and its metabolic interaction with

85 gliclazide. Considering the complexity associated with the combination of aprepitant and

86 gliclazide, this study was designed to evaluate the influence of aprepitant on the

87 pharmacodynamics (PD) and pharmacokinetics (PK) of gliclazide in rodent (normal and alloxan-

88 induced diabetic rats) and non-rodent (rabbits) animal models.

89

90

91

92

93

94

95

96

97

98

99

100

101

102

103

\section{MATERIAL AND METHODS}

\section{Materials}

Aprepitant and gliclazide were gift samples from Dr. Reddy's Laboratories (Hyderabad, India). Glucose Kits (Span Diagnostics) were procured from a local pharmacy. Alloxan monohydrate, orthophosphoric acid, acetonitrile, dichloromethane and other relevant analytical reagents were procured from SD Fine Chemicals Limited, (Mumbai, India) and Loba Chemie Private Limited (Mumbai, India).

\section{Animals}

The animals (albino rats and rabbits - both male and female) were purchased from Mahaveer Enterprises (Hyderabad, India). For this study, the rats with 220-270 g weight and 6-8 weeks of age, and rabbits with $1.35-1.75 \mathrm{Kg}$ weight and 3 months of age were selected. Throughout the study, animals were housed individually in polypropylene cages with specific identification number. The experimental animals were provided with a standard autoclaved commercial diet and filtered water ad libitum. Animals were fasted for $18 \mathrm{hr}$ prior to the dosing and dietary restrictions were followed during experimentation. 
104

105

106

107

108

109

110

111

112

113

114

115

116

117

118

119

120

121

122

123

124

125

\section{Study design}

As represented in Figure 1, this study was designed considering the all important factors to correlate the preclinical results to the clinical scenario. This study plan was approved by an Institutional Animal Ethics Committee (IAEC) (Registration Number 516/01/A/CPCSEA). The study was performed as per the recommendations of the Committee for the Purpose of Control, and Supervision of Experiments on Animals (CPCSEA) guidelines.

The main steps in this study are:

(1) Selection of the animal models

(2) Dose selection of the experimental drugs (aprepitant and gliclazide)

(3) Pharmacodynamic interaction studies in normal and diabetic rats

(4) Pharmacodynamic and pharmacokinetic interaction studies in rabbits

(5) Pharmacokinetic and statistical analysis

In rats and rabbits, as represented in Figure 1, the activity (PD and PK) of gliclazide was evaluated in the presence of acute (single dose administration) and successively chronic (multiple dose administration for 7 days) treatment with an interacting drug (aprepitant).

\section{Selection of the animal models}

It is well known fact that the preclinical PK/PD results from one animal model can't be correlated directly with humans due to the existence of interspecies differences. The identification and characterization of any interaction (PD or PK) in two dissimilar species at different conditions (normal and diabetic) will certainly validate the possible existence of that interaction in humans. Hence, the selection of relevant animal models is a crucial factor in the 
126 evaluation of drug-drug interactions. Rodents (normal and alloxan-induced diabetic rats) and

127 non-rodents (rabbits) were selected as animal models $(n=6)$ for this study.

128

129

130

131

132

133

134

135

136

137

138

139

140

141

142

144

145

146

147

Dose selection of the experimental drugs (aprepitant and gliclazide)

To mimic the clinical scenario, the dose of the experimental drugs was determined by extrapolating the human oral therapeutic dose (aprepitant $=125 \mathrm{mg}$; gliclazide $=80 \mathrm{mg}$ ) (Summary of Product Characteristics) to rats and rabbits based on body surface area. The human equivalent dose of aprepitant in rats and rabbits is $11.25 \mathrm{mg} / \mathrm{kg}$ b.wt and $8.75 \mathrm{mg} / 1.5 \mathrm{~kg} \mathrm{b.wt}$, respectively. The human equivalent dose of gliclazide in rabbits is $5.6 \mathrm{mg} / 1.5 \mathrm{~kg}$ b.wt. Based on previous studies and considering the preliminary dose effect-relationship results (Figure 2), the dose of gliclazide in rats was determined as $2 \mathrm{mg} / \mathrm{kg}$ b.wt. Both gliclazide and aprepitant were administered to the respective animal groups by oral gavage (Mastan \& Kumar, 2009).

\section{Pharmacodynamic interaction studies in normal and diabetic rats}

Pharmacodynamic interaction studies were conducted in two groups (normal and alloxaninduced diabetic rats) containing 6 animals each. Diabetes in albino rats was induced by the intraperitoneal injection of alloxan monohydrate $(100 \& 50 \mathrm{mg} / \mathrm{kg} \mathrm{b}$.wt) for 2 consecutive days prior to entry into the study. Rats with a blood glucose level $>11.10 \mathrm{mmol} / \mathrm{L} 3$ days following the injection were considered as diabetic and selected for the study (Mastan \& Kumar, 2009).

For a single dose interaction phase, in each group, after an acclimatization period of 5 days, an oral dose of gliclazide was administered to each group. After 7 days washout period, an oral single dose of interacting drug (aprepitant) was administered. After 7 days washout period, a combination of single dose of aprepitant and gliclazide were administered with a time interval of 30 minutes. After this single dose interaction phase, the respective animal groups were continued 
148 for chronic treatment (multiple dose administration) with an interacting drug (aprepitant) for 7

149 days with a regular feeding. On $8^{\text {th }}$ day, a combination of single dose of aprepitant and gliclazide

150 were administered with a time interval of 30 minutes.

Blood samples were collected at 0 (predose), 1, 2,3,4,6,8,10 and $12 \mathrm{hr}$ from retro orbital

152 plexus of each rat. Blood glucose was determined from these samples by GOD/POD method and

153

154

155

156

157

158

159

160

161

162

163

164

165

166

167

168

169

170

serum insulin was determined (at 2 and $8 \mathrm{hr}$ ) by ELISA method (Lequin, 2005) using a commercial kit (Mercodia) at Biological E Limited (Hyderabad, India).

\section{Pharmacodynamic and pharmacokinetic interaction studies in rabbits}

The experimental design for in rabbits is similar to the rats as detailed above. The major difference in rabbits study is simultaneous determination of pharmacodynamic and pharmacokinetic parameters from the blood samples which were collected at 0 (predose), 1, 2, 3, $4,6,8,10,12,16,20$ and $24 \mathrm{hr}$ from the marginal ear vein of each rabbit. Blood glucose was determined by GOD/POD method and serum insulin was determined (at $3 \mathrm{hr}$ ) by ELISA method.

\section{Pharmacokinetic and statistical analysis}

Gliclazide concentration levels were determined by HPLC method (Kumar et al., 2007; Kumar \& Mastan, 2011). Non-compartmental PK analysis was conducted by Phoenix WinNonlin software to determine the PK parameters of gliclazide. The maximum concentration $\left(\mathrm{C}_{\max }\right)$ and time for the maximum concentration $\left(\mathrm{T}_{\max }\right)$ were observed values directly from the concentration and time data of gliclazide in rabbits. The Area Under the Curve (AUC) and Area Under the Moment Curve (AUMC) were determined by the linear trapezoidal rule. The elimination rate constant $\left(\mathrm{K}_{\mathrm{el}}\right)$ was determined by log-linear regression of concentration-time data during the terminal elimination phase. The Mean Residence Time (MRT) was determined by the ratio of 
171 AUMC and AUC. The terminal half-life of gliclazide $\left(t_{1 / 2}\right)$ was determined by the ratio of 0.693

172 and $\mathrm{K}_{\mathrm{el}}$ (Kumar \& Mastan, 2011). Statistical analysis was conducted by student's paired t-test.

\section{RESULTS}

174

175

176

177

178

179

180

181

182

183

184

185

186

187

188

189

190

191

192

193

\section{Pharmacodynamic interaction studies in rats}

\section{Influence of aprepitant on gliclazide blood glucose reduction}

The mean percent blood glucose reduction of gliclazide in presence and absence of aprepitant in normal and diabetic rats is represented in Table 1. In normal rats, gliclazide produced hypoglycemic activity with maximum biphasic glucose reduction of $36.99 \pm 2.90 \%$ and $35.94 \pm$ $2.66 \%$ at 2 and $8 \mathrm{hr}$. In diabetic rats, gliclazide produced anti-hyperglycemic activity with maximum biphasic glucose reduction of $39.83 \pm 1.54 \%$ and $38.91 \pm 3.68 \%$ at 2 and $8 \mathrm{hr}$. These results suggest that the blood glucose reduction with gliclazide treatment was higher in diabetic condition compared to normal condition. The maximum blood glucose reduction $(18.50 \pm 7.72 \%$ in normal rats and $19.91 \pm 1.82 \%$ in diabetic rats) was observed at $2 \mathrm{hr}$ with the interacting drug (aprepitant) in rats. The gliclazide blood glucose reduction was significantly increased in the presence of aprepitant in normal (single vs. multiple dose treatment: at $2 \mathrm{hr}, 52.29 \pm 6.62 \%$ and $60.81 \pm 8.15 \%$; at $8 \mathrm{hr}, 49.42 \pm 8.63 \%$ and $55.44 \pm 5.57 \%$ ) rats (Table 1 ). The gliclazide blood glucose reduction was significantly increased in the presence of aprepitant in diabetic (single vs. multiple dose treatment: at $2 \mathrm{hr}, 56.36 \pm 1.87 \%$ and $63.44 \pm 3.65 \%$; at $8 \mathrm{hr}, 51.30 \pm 2.61 \%$ and $56.64 \pm 2.56 \%)$ rats (Table 1$).$

\section{Influence of aprepitant on gliclazide insulin levels}

92 The mean insulin levels of gliclazide in presence and absence of aprepitant in normal and diabetic rats is represented in Figure 3. The insulin levels observed with gliclazide treatment 
194 were $18.48 \pm 0.24 \mu \mathrm{U} / \mathrm{mL}$ (at $2 \mathrm{hr}$ ) and $18.08 \pm 0.18 \mu \mathrm{U} / \mathrm{mL}$ (at $8 \mathrm{hr}$ ) in normal rats. In diabetic

195 rats, insulin levels observed with gliclazide treatment were $9.33 \pm 1.43 \mu \mathrm{U} / \mathrm{mL}$ (at $2 \mathrm{hr}$ ) and 8.19

$196 \pm 1.24 \mu \mathrm{U} / \mathrm{mL}$ (at $8 \mathrm{hr}$ ). In normal rats, the insulin levels observed with aprepitant treatment were

$19717.12 \pm 0.11 \mu \mathrm{U} / \mathrm{mL}$ and $17.0 \pm 0.45 \mu \mathrm{U} / \mathrm{mL}$ at 2 and $8 \mathrm{hr}$, respectively. In diabetic rats, the

198 insulin levels observed with aprepitant treatment were $7.44 \pm 0.31$ and $7.14 \pm 0.10$ at 2 and $8 \mathrm{hr}$,

199 respectively. The insulin levels were significantly increased in the presence of aprepitant in 200 normal (single vs. multiple dose treatment: at $2 \mathrm{hr}, 20.22 \pm 0.87$ and $22.05 \pm 1.05 \mu \mathrm{U} / \mathrm{mL}$; at 8

$201 \mathrm{hr}, 19.85 \pm 1.17$ and $20.24 \pm 1.39 \mu \mathrm{U} / \mathrm{mL}$ ) rats (Figure 3). The insulin levels were significantly 202 increased in the presence of aprepitant in diabetic (single vs. multiple dose treatment: at $2 \mathrm{hr}$, $20311.25 \pm 1.15$ and $12.97 \pm 0.51 \mu \mathrm{U} / \mathrm{mL}$; at $8 \mathrm{hr}, 9.09 \pm 0.83$ and $10.14 \pm 0.90 \mu \mathrm{U} / \mathrm{mL}$ ) rats (Figure $2043)$.

205

Pharmacodynamic and pharmacokinetic interaction studies in rabbits

207

\section{Influence of aprepitant on gliclazide blood glucose reduction}

209

210

211

212

213

214

215

216

The pharmacodynamic interaction results summary of gliclazide and aprepitant in rabbits is represented in Table 2. In rabbits, gliclazide produced hypoglycemic activity with maximum glucose reduction of $36.65 \pm 5.61 \%$ at $3 \mathrm{hr}$. The blood glucose reduction observed with aprepitant was $14.14 \pm 3.11 \%$ in rabbits. The gliclazide blood glucose reduction was significantly increased in the presence of aprepitant in rabbits (single vs. multiple dose treatment: $44.62 \pm 4.98 \%$ and $48.87 \pm 5.17 \%)$. 
217 Influence of aprepitant on gliclazide insulin levels

218 The mean insulin levels of gliclazide in presence and absence of aprepitant in rabbits is

219 represented in Figure 3. The insulin level observed with gliclazide treatment was $13.19 \pm 0.90$

$220 \mu \mathrm{U} / \mathrm{mL}$ at $3 \mathrm{hr}$ in rabbits. The insulin level observed in rabbits with aprepitant treatment was

$22110.55 \pm 0.25 \mu \mathrm{U} / \mathrm{mL}$ at $3 \mathrm{hr}$. The insulin levels were significantly increased in the presence of

222 aprepitant in rabbits (single vs. multiple dose treatment: $14.16 \pm 0.62$ and $15.99 \pm 0.79 \mu \mathrm{U} / \mathrm{mL}$ ).

223

224

225

226

227

228

229

230

231

232

233

234

235

236

237

238

239

240

241

\section{Influence of aprepitant on gliclazide pharmacokinetics}

The mean concentration and time profile of gliclazide in presence and absence of aprepitant is represented in Figure 4. The influence of aprepitant on mean PK parameters of gliclazide is represented in Table 3. There was a significant increase in concentration levels and an alteration in the pharmacokinetic parameters (increase in $\mathrm{C}_{\max }$, $\mathrm{AUC}$ and MRT; decrease in clearance fraction) of gliclazide in the presence of aprepitant in rabbits.

\section{DISCUSSION}

It is well known fact that several drugs have been withdrawn from the market due to their potent drug-drug interactions (Thorir et al., 2003). Hence, an evaluation of possible mechanisms of drug-drug interactions have become a cornerstone in the effective treatment of chronic diseases in which concomitant administration of multiple drugs is a very common phenomenon.

Considering the interspecies differences, this study was carefully designed to get precise and validated results from the selected animal models. The major advantages of this study are (i) an extrapolated human oral therapeutic doses of the experimental drugs to rats and rabbits to mimic the actual clinical scenario, (ii) determined the pharmacodynamic activity (blood glucose reduction in specified time intervals and insulin estimation at the time of peak concentrations) of 
242 gliclazide in normal and diabetic condition, (iii) obtained results from two dissimilar species (rats

243 and rabbits) for the precise identification, characterization and validation of the interaction, (iv)

244 determined the acute and chronic influence of aprepitant on gliclazide activity, (v) determined

245 the mechanism of pharmacokinetic interaction between aprepitant and gliclazide.

246 The rats are more sensitive to gliclazide effect compared to other animals and hence

247 relevant dose selection is very crucial in drug-drug interaction studies. Hence, based on dose-

248 response relationship study of gliclazide, the dose $(2 \mathrm{mg} / \mathrm{kg} \mathrm{b} . \mathrm{wt})$ which can produce a blood

249 glucose reduction of 30 to $35 \%$ was selected for the interaction studies in rats. The results from

250 our dose-response relationship study are in compliance to the previous reports Satyanarayana \&

251 Kumar, 2006; Mastan \& Kumar, 2009; Kumar \& Mastan, 2011).

252 Gliclazide produced a biphasic maximum response at 2 and $8 \mathrm{hr}$ in rats which is probably

253 due to an enterohepatic circulation (biliary excretion) of gliclazide as reported in previous animal

254 studies and humans. The biphasic blood glucose reduction was not observed in rabbits

255 confirming that there was no enterohepatic circulation (biliary excretion) of gliclazide in rabbits

256 which is in consistent with the published studies (Satyanarayana \& Kumar, 2006; Mastan \&

257 Kumar, 2009; Kumar \& Mastan, 2011). In rats and rabbits, aprepitant had shown some marginal

258 tendency to decrease the blood glucose and strong effects on insulin levels. The possible reason

259 for this tendency is the inhibition of substance P release by aprepitant and its eventual relation

260 with the decrease in blood glucose level (Brown \& Vale, 1976; Karagiannides et al., 2011). In

261 combination, the pharmacodynamic activity of gliclazide was significantly influenced by

262 aprepitant in normal and diabetic condition. From these pharmacodynamic results, it appears to

263 be an additive effect with the concomitant administration of aprepitant and gliclazide considering

264 the individual contribution of aprepitant on blood glucose (modest effect) and insulin (strong 
265 effect) in rats and rabbits. However, in pharmacokinetic study in rabbits, the gliclazide 266 concentrations were significantly increased following the single- and multiple-dose treatment of 267 aprepitant in rabbits. The increased concentrations and significantly altered pharmacokinetic 268 parameters of gliclazide clearly indicate that there is a significant pharmacokinetic interaction 269 between aprepitant and gliclazide. The increase in $\mathrm{C}_{\max }$ and AUC (bioavailability) of gliclazide 270 in the presence of aprepitant suggesting that bioavailability of gliclazide was increased. The 271 increase in bioavailability, increase in MRT and significant decrease in gliclazide clearance 272 confirms the decrease in gliclazide metabolism by aprepitant. The significant inhibition of 273 CYP3A4 by aprepitant with other drugs was reported in various studies (Loose et al., 2007;

274 Shindorf et al., 2013; Apro et al., 2010; Majumdar et al., 2003). In general, CYP3A4 inhibition is 275 relatively higher with chronic administration of a drug and this phenomenon is reflected in our 276 study (increase in concentrations, bioavailability and MRT, and, decrease in clearance of 277 gliclazide). The possible mechanism of interaction is inhibition of CYP3A4 by aprepitant 278 resulted in decrease in gliclazide metabolism and subsequently increases in gliclazide concentrations and bioavailability in rabbits. Overall, this study reasonably confirm that (a) the inhibition of CYP3A4 by aprepitant indeed lead to increased gliclazide concentrations and subsequently increased glucose reduction, (b) in addition, the gliclazide pharmacodynamic activity was further influenced by the individual contribution of aprepitant on blood glucose (modest effect) and insulin (strong effect) in animal models.

Despite the highlights of this study, we admit that there are some limitations. Firstly, the pharmacokinetic study was not evaluated in diabetic condition. Second, there is no concomitant warrants further study to explore these parameters. 
288 CONCLUSION

289 In combination, aprepitant significantly influenced the pharmacodynamic activity of gliclazide in 290 animal models. Considering this, care should be taken when this combination is prescribed for 291 the clinical benefit in diabetic patients.

292

293 ACKNOWLEDGEMENTS

294 The authors are thankful to M/s. Dr. Reddy's Laboratories, Hyderabad for supplying gift samples 295 of the experimental drugs for this study.

296

297

298

299

300

301

302

303

304

305 
306

307

308

309

310

311

312

313

314

315

316

317

318

319

320

321

322

323

324

325

326

327

328

\section{REFERENCES}

Aapro MS, Walko CM. 2010.Aprepitant: drug-drug interactions in perspective, Annals of Oncology 21(12):2316-2323. DOI:10.1093/annonc/mdq149

Alvares OF, Meyer J. 1971. Current concepts of the histology of the oral mucosa. In: Squier C.A., Meyer J. (Eds.) Current concepts of the histology of the oral mucosa. Charles C. Thomas, Springfield, IL.97p.

Anna D, Julie K, Antonia C, Paiboon J. 2017.Drug interactions with aprepitant or fosaprepitant: Review of literature and implications for clinical practice. J Oncol Pharm Practice 1-13. DOI: $10.1177 / 1078155216631408$.

Bergese S, Viloria A, Uribe A, Antor A, Fernandez S. 2012. Aprepitant versus ondansetron in preoperative triple-therapy treatment of nausea and vomiting in neurosurgery patients: study protocol for a randomized controlled trial. Trials 13:130. DOI:10.1186/1745-621513-130.

Brown M, Vale W. 1976. Effects of neurotensin and substance P on plasma insulin, glucagonand glucose levels.Endocrinology.98(3):819-22.

Chong K, Dhatariya K. 2009. A case of severe, refractory diabetic gastroparesis managed by prolonged use of aprepitant. Nat Rev Endocrinol 5(5):285-288. DOI $10.1038 /$ nrendo. 2009.50

Curtis T.2006.Drug Interactions of Medications Commonly Used in Diabetes.Diabetes Spectrum 19(4):202-211. DOI: 10.2337/diaspect.19.4.202.

Fava D, Cassone-Faldetta M, Laurenti O, De Luca O, Ghiselli A, De Mattia G. 2002. Gliclazide improves anti-oxidant status and nitric oxide-mediated vasodilation in Type 2 diabetes. Diabetic Medicine19:752-757. DOI: 10.1046/j.1464-5491.2002.00762.x. 
329 Fountoulakis N, Dunn J, Thomas S, Karalliedde J. 2017. Successful management of refractory

330 diabetic gastroparesis with long-term Aprepitant treatment. Diabetic Medicine 34(10). DOI: $10.1111 /$ dme.13413.

332 Global Burden of Disease (GBD).2016.Disease and Injury Incidence and Prevalence

333

334

335

336

337

338

339

340

341

342

343

344

345

346

347

348

349
Collaborators. Global, regional, and national incidence, prevalence, and years live with disability for 310 diseases and injuries, 1990-2015: a systematic analysis for the Global Burden of Disease Study 2015. Lancet 88:1545-602.DOI:10.1016/S0140-

$6736(16) 31678-6$

Julie RI, John AJ.2017. Increase in the Incidence of Diabetes and Its Implications. $N$ Engl J Med 376:1473-1474. DOI: 10.1056/NEJMe1616575.

Karagiannides I, Bakirtzi K, Kokkotou E, Stavrakis D, Margolis, KG, Thomou T, Pothoulakis, C. 2011. Role of Substance P in the Regulation of Glucose Metabolism via Insulin Signaling-AssociatedPathways. Endocrinology 152(12):4571-4580.

Kumar KE, Ramesh A, Yadav RS, Satyanarayana S. 2007. Determination of gliclazide in rabbit serum by RP-HPLC. Acta Ciencia Indica Chem 33:273-278.

Kumar KE, Mastan S. 2011.Influence of Efavirenz and Nevirapine on the Pharmacodynamics and Pharmacokinetics of Gliclazide in Rabbits. Journal of Endocrinology and Metabolism 1:113-124.DOI: 10.4021/jem34w.

Lequin R. 2005. Enzyme immunoassay (EIA)/enzyme-linked immunosorbent assay (ELISA). Clin. Chem. 51(12): 2415-2418.

Loos WJ, de Wit R, Freedman SJ, Van Dyck K, Gambale JJ, Li S, Murphy GM, Van NC, 
350

351

352

353

354

355

356

357

358

359

360

361

362

363

364

365

366

367

368

369

370

371

DeBrujin P, Verweij J. 2007.Aprepitant when added to a standard antiemetic regimen consisting of ondansetron and dexamethasone does not affect vinorelbine pharmacokinetics in cancer patients. Cancer Chemo Pharmacol 59:407-412.

Majumdar AK, McCrea JB, Panebianco DL, Hesney M, Dru J, Constanzer M, Goldberg M.R, Murphy G, Gottesdiener KM, Lines CR, Petty KJ, Blum RA. 2003. Effects of aprepitant on cytochrome P450 3A4 activity using midazolam as a probe. Clinical Pharmacology \& Therapeutics 74:150-156. DOI:10.1016/S0009-9236(03)00123-1.

Mastan S, Kumar KE. 2009. Influence of non-nucleoside reverse transcriptase inhibitors (efavirenz and nevirapine) on the pharmacodynamic activity of gliclazide in animal models. Diabetology and Metabolic Syndrome 1:15. DOI:10.1186/1758-5996-1-15

O'Brien RC, Luo M, Balazs N, Mercuri J. 2000. In vitro and in vivo antioxidant properties of gliclazide. Journal of Diabetes Complications 14:201-206. DOI: 10.1016/S1056$8727(00) 00084-2$

Peron EP, Ogbonna KC, Donohoe KL.2015. Diabetic Medications and Polypharmacy. Clinics in Geriatric Medicine 31(1):17-27. DOI: 10.1016/j.cger.2014.08.017.

Satyanarayana S, Kilari EK.2006.Influence of nicorandil on the pharmacodynamics and pharmacokinetics of gliclazide in rats and rabbits.Mol Cell Biochem 291(1-2):101-5. DOI: $10.1007 / \mathrm{s} 11010-006-9202-\mathrm{y}$.

Schernthaner G. 2003.Gliclazide modified release: A critical review of pharmacodynamic, metabolic, and vasoprotective effects. Metabolism 52:29-34. DOI:10.1016/S00260495(03)00215-4.

Shadle CR, Lee Y, Majumdar AK, Petty KJ, Gargano C, Bradstreet TE, Evans JK, Blum RA. 
372

373

374 Shindorf ML, Manahan KJ, Geisler JP.2013.The interaction of ifosfamide and aprepitant in 375

376

377

378

379

380

381

382

383

384
2004. Evaluation of potential inductive effects of aprepitant on cytochrome P450 3A4 and 2C9 activity. J Clin Pharmacol 44:215-223. gynecologic malignancies. Gynecologic Oncology Case Reports 6:34-35. DOI:10.1016/j.gynor.2013.06.002.

Thorir DB, John TC, Heidi JE, Volker F, Lawrence G, Scott G, John KS, Peter K, Gerald M, Lan N, Gondi K, James M, Obach RS, Stanley R, Amy R, Anita S, Fred S, John TS, Donald T, Jose MV, John W, Steven AW.2003. The conduct of in vitro and in vivo drugdrug interaction studies: a pharmaceutical research and manufacturers of america (phrma) perspective. Drug Metabolism and Disposition 31 (7): 815-832. DOI: $\underline{10.1124 / \mathrm{dmd} .31 .7 .815 .}$

Ziegler O, Drouin P. 1994. Hemobiological properties of gliclazide. Journal of Diabetes Complications 8:235-239. DOI:10.1016/1056-8727(94)90050-7. 


\section{Table $\mathbf{1}$ (on next page)}

Mean percent blood glucose reduction of gliclazide in presence and absence of aprepitant administration in normal and diabetic rats $(n=6)$

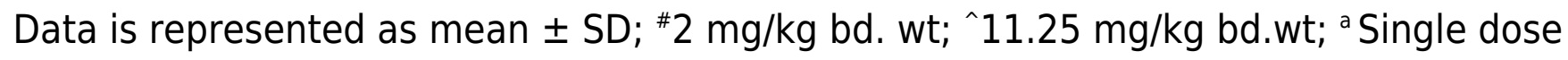

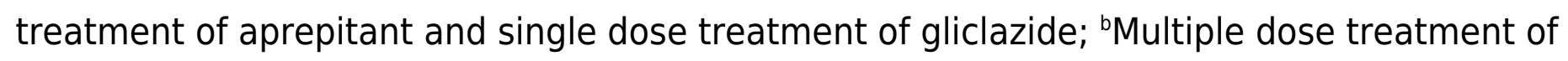
aprepitant ( 7 days) and single dose treatment of gliclazide; $* * P<0.01$ compared to gliclazide group; *** $\mathrm{P}<0.001$ compared to gliclazide group 


\begin{tabular}{|c|c|c|c|c|c|c|c|c|}
\hline \multirow[b]{2}{*}{$\begin{array}{l}\text { Time } \\
\text { (hr) }\end{array}$} & \multicolumn{2}{|l|}{ Normal rats } & \multicolumn{6}{|c|}{ Alloxan induced diabetic rats } \\
\hline & Gliclazide $^{\#}$ & Aprepitant ${ }^{\wedge}$ & $\begin{array}{l}\text { Aprepitant + } \\
\text { Gliclazide } \\
\text { (Single dose }_{\text {treatment) }} \\
\text { treatme }^{2}\end{array}$ & $\begin{array}{l}\text { Aprepitant + } \\
\text { Gliclazide } \\
\text { (Multiple dose }^{\text {(reatment) }} \\
\text { treat }^{\text {b }}\end{array}$ & Gliclazide $^{\#}$ & Aprepitant ${ }^{\wedge}$ & $\begin{array}{l}\text { Aprepitant }+ \\
\text { Gliclazide } \\
\text { (Single dose }^{\text {treatment) }} \\
\text { treatmen }^{\text {a }}\end{array}$ & $\begin{array}{l}\text { Aprepitant }+ \\
\text { Gliclazide } \\
\text { (Multiple dose } \\
\text { treatment) }^{\mathrm{b}}\end{array}$ \\
\hline 1 & $10.30 \pm 3.42$ & $03.31 \pm 9.70$ & $21.01 \pm 6.54 * *$ & $29.18 \pm 5.87^{* * *}$ & $13.20 \pm 1.71$ & $07.11 \pm 2.09$ & $20.34 \pm 1.39^{* * *}$ & $34.31 \pm 1.52 * * *$ \\
\hline 2 & $36.99 \pm 2.90$ & $18.50 \pm 7.72$ & $52.29 \pm 6.62 * * *$ & $60.81 \pm 8.15^{* * *}$ & $39.83 \pm 1.54$ & $19.91 \pm 1.82$ & $56.36 \pm 1.87 * * *$ & $63.44 \pm 3.65^{* * *}$ \\
\hline 3 & $30.14 \pm 5.59$ & $15.84 \pm 8.53$ & $44.42 \pm 7.46^{* *}$ & $52.67 \pm 6.45^{* * *}$ & $30.73 \pm 2.75$ & $15.11 \pm 2.19$ & $39.15 \pm 2.70 * * *$ & $45.14 \pm 2.25^{* * *}$ \\
\hline 4 & $26.42 \pm 8.73$ & $14.34 \pm 8.75$ & $41.85 \pm 5.53^{* *}$ & $50.11 \pm 4.93 * * *$ & $28.52 \pm 2.22$ & $12.16 \pm 2.83$ & $36.91 \pm 3.20 * * *$ & $38.77 \pm 3.30^{* * *}$ \\
\hline 10 & $19.64 \pm 8.29$ & $08.63 \pm 7.36$ & $26.46 \pm 6.97$ & $37.27 \pm 6.12^{* *}$ & $31.68 \pm 2.98$ & $09.29 \pm 2.77$ & $36.49 \pm 2.30 * *$ & $39.92 \pm 2.35^{* * *}$ \\
\hline 12 & $10.40 \pm 12.89$ & $06.90 \pm 8.02$ & $20.75 \pm 5.96$ & $31.00 \pm 5.27^{* *}$ & $16.42 \pm 1.85$ & $06.31 \pm 2.86$ & $26.12 \pm 2.06^{* * *}$ & $29.51 \pm 2.07 * * *$ \\
\hline
\end{tabular}




\section{Table 2 (on next page)}

Mean percent blood glucose reduction of gliclazide in presence and absence of aprepitant administration in normal rabbits $(n=6)$

Data is represented as mean $\pm \mathrm{SD}$; ${ }^{*} 5.6 \mathrm{mg} / 1.5 \mathrm{~kg} \mathrm{~b} . w t ;$; $8.75 \mathrm{mg} / 1.5 \mathrm{~kg} \mathrm{bd}$. wt; ' Single dose treatment of aprepitant and single dose treatment of gliclazide; ' ${ }^{\mathrm{M}}$ Multiple dose treatment of aprepitant ( 7 days) and single dose treatment of gliclazide; $* P<0.05$ compared to gliclazide group; $* * P<0.01$ compared to gliclazide group; $* * * P<0.001$ compared to gliclazide group. 


\begin{tabular}{|c|c|c|c|c|}
\hline $\begin{array}{l}\text { Time } \\
\text { (hr) }\end{array}$ & Gliclazide $^{\#}$ & Aprepitant ${ }^{\wedge}$ & $\begin{array}{l}\text { Aprepitant }+ \text { Gliclazide } \\
\text { (Single dose treatment) }^{\mathrm{a}}\end{array}$ & $\begin{array}{l}\text { Aprepitant }+ \text { Gliclazide } \\
\text { (Multiple dose treatment) }\end{array}$ \\
\hline 1 & $10.45 \pm 3.41$ & $02.19 \pm 1.12$ & $08.28 \pm 2.07$ & $09.67 \pm 1.79$ \\
\hline 2 & $19.28 \pm 6.69$ & $05.40 \pm 1.29$ & $24.08 \pm 4.76$ & $26.13 \pm 6.55$ \\
\hline 3 & $36.65 \pm 5.61$ & $09.73 \pm 2.50$ & $44.62 \pm 4.98 *$ & $48.87 \pm 5.17^{*}$ \\
\hline 4 & $23.39 \pm 5.12$ & $14.14 \pm 3.11$ & $37.89 \pm 4.17 * * *$ & $41.18 \pm 2.44 * * *$ \\
\hline 6 & $17.84 \pm 4.52$ & $12.19 \pm 2.24$ & $29.47 \pm 3.41^{* * *}$ & $34.37 \pm 5.07 * * *$ \\
\hline 8 & $12.76 \pm 5.80$ & $09.79 \pm 2.51$ & $25.12 \pm 4.17 * *$ & $30.75 \pm 5.50 * * *$ \\
\hline 10 & $10.93 \pm 5.39$ & $08.13 \pm 3.03$ & $22.74 \pm 4.52 * *$ & $26.93 \pm 5.04 * * *$ \\
\hline 12 & $07.63 \pm 5.66$ & $06.23 \pm 2.33$ & $17.31 \pm 4.52^{* *}$ & $23.52 \pm 5.38 * * *$ \\
\hline 16 & $05.86 \pm 4.91$ & $04.38 \pm 2.36$ & $12.06 \pm 4.80$ & $19.27 \pm 5.64 * *$ \\
\hline 20 & $04.30 \pm 4.51$ & $02.67 \pm 1.98$ & $08.52 \pm 5.21$ & $14.84 \pm 7.14^{*}$ \\
\hline 24 & $02.83 \pm 4.07$ & $01.54 \pm 1.83$ & $04.22 \pm 5.33$ & $11.53 \pm 6.03^{*}$ \\
\hline
\end{tabular}




\section{Table 3 (on next page)}

Mean pharmacokinetic parameters of gliclazide before and after aprepitant administration in normal rabbits $(n=6)$

Data is expressed as mean $\pm \mathrm{SD}$; ${ }^{*} 5.6 \mathrm{mg} / 1.5 \mathrm{~kg} \mathrm{~b}$.wt; ${ }^{8} 8.75 \mathrm{mg} / 1.5 \mathrm{~kg} \mathrm{bd}$. wt; ${ }^{\text {a }}$ Single dose

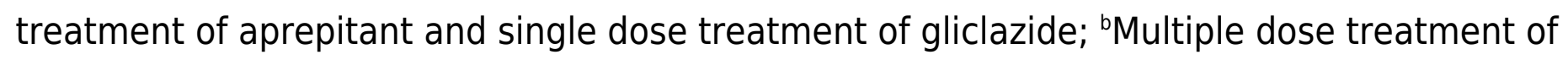
aprepitant ( 7 days) and single dose treatment of gliclazide $C \max =$ Maximum concentration; Tmax = Time to maximum concentration; $C L=$ Clearance; $\mathrm{Vd}=$ Volume of distribution; $T_{1 / 2}=$ Half-life; $A U C=$ Area under the curve; $M R T=$ Mean residence time; $* \mathrm{P}<0.05$ compared to gliclazide group; $* * P<0.001$ compared to gliclazide group. 


\begin{tabular}{|c|c|c|c|}
\hline Parameter & Gliclazide $^{\#}$ & Aprepitant ${ }^{\wedge}$ & $\begin{array}{l}\text { Aprepitant }+ \text { Gliclazide } \\
\text { (Single dose treatment) }^{\mathrm{a}}\end{array}$ \\
\hline $\mathrm{C}_{\max }(\mathrm{ng} / \mathrm{mL})$ & $360.11 \pm 7.36$ & $398.73 \pm 7.42 * *$ & $426.97 \pm 7.62 * *$ \\
\hline $\mathrm{T}_{\max }(\mathrm{hr})$ & $03.0 \pm 0.00$ & $03.0 \pm 0.00$ & $03.0 \pm 0.00$ \\
\hline $\mathrm{CL}(\mathrm{mL} / \mathrm{hr})$ & $0.00127 \pm 0.00$ & $0.00110 \pm 0.00^{*}$ & $0.00094 \pm 0.00 * *$ \\
\hline $\mathrm{Vd}(\mathrm{mL})$ & $0.01284 \pm 0.00$ & $0.01202 \pm 0.00$ & $0.01114 \pm 0.00$ \\
\hline $\mathrm{T}_{1 / 2}(\mathrm{hr})$ & $7.12 \pm 1.98$ & $7.63 \pm 1.38$ & $8.49 \pm 2.92$ \\
\hline $\operatorname{AUC}_{0-24}(\mathrm{ng} \cdot \mathrm{hr} / \mathrm{mL})$ & $3882.70 \pm 125.54$ & $4407.63 \pm 38.71 * *$ & $4968.08 \pm 155.17^{* *}$ \\
\hline $\mathrm{AUC}_{0 \text {-inf }}(\mathrm{ng} \cdot \mathrm{hr} / \mathrm{mL})$ & $4419.37 \pm 335.65$ & $5113.23 \pm 185.99^{*}$ & $6030.07 \pm 793.69^{*}$ \\
\hline $\mathrm{AUMC}_{0-24}(\mathrm{ng} \cdot \mathrm{hr} / \mathrm{mL})$ & $35455.33 \pm 1775.56$ & $41606.67 \pm 693.27^{* *}$ & $47811.67 \pm 2889.41 * *$ \\
\hline $\operatorname{MRT}_{0-24}(\mathrm{hr})$ & $9.13 \pm 0.21$ & $9.44 \pm 0.08^{*}$ & $9.62 \pm 0.29 *$ \\
\hline $\mathrm{MRT}_{0 \text {-inf }}(\mathrm{hr})$ & $12.21 \pm 1.72$ & $12.99 \pm 1.04$ & $14.34 \pm 3.20$ \\
\hline
\end{tabular}

1 


\title{
Figure 1 (on next page)
}

\author{
Experimental design
}




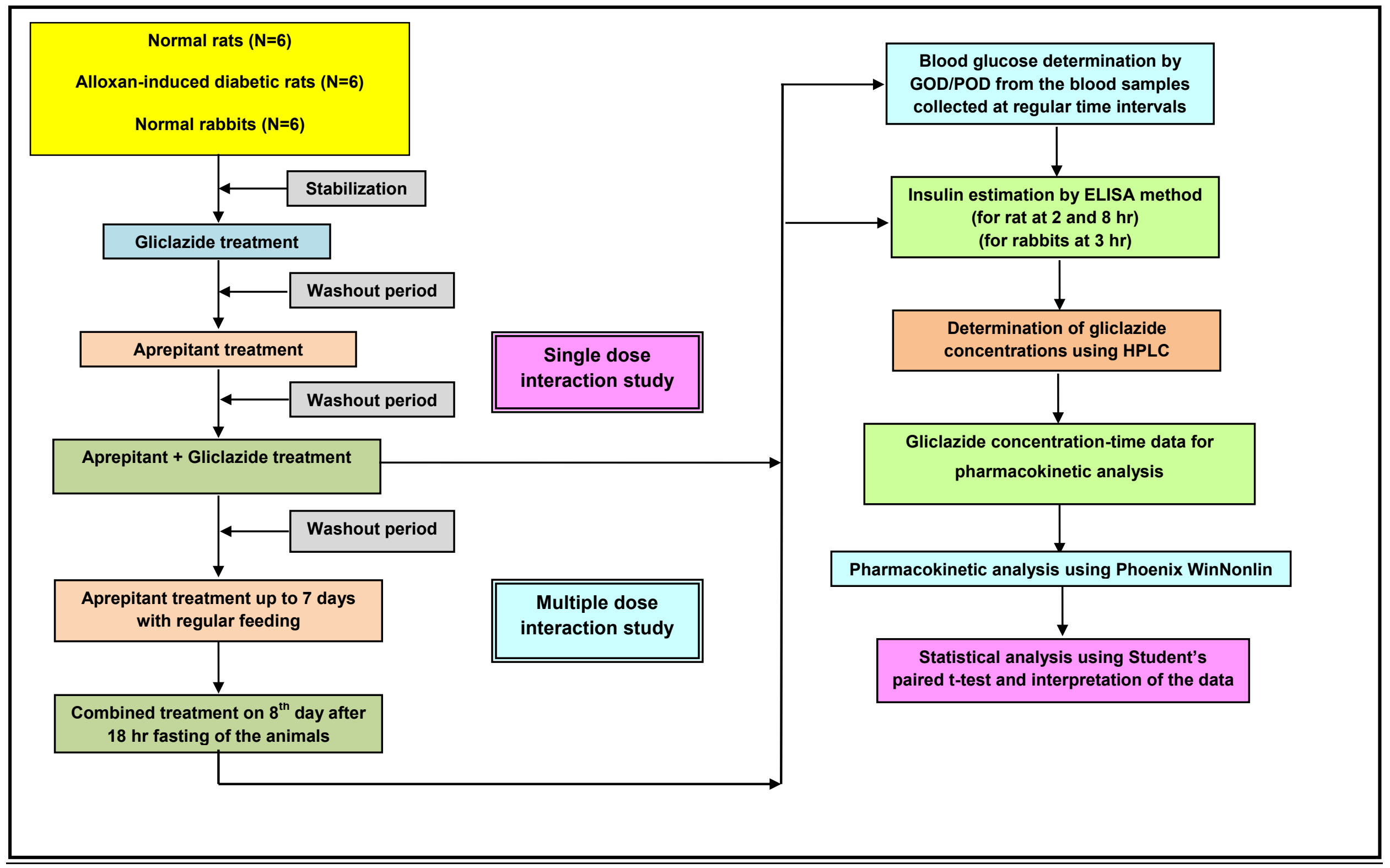


Figure 2

The dose-effect relationship of gliclazide on blood glucose in normal rats $(N=6)$

Blue = Gliclazide $1 \mathrm{mg} / \mathrm{kg}$ bd. wt.; Red = Gliclazide $2 \mathrm{mg} / \mathrm{kg}$ bd. wt.; Green = Gliclazide 4 $\mathrm{mg} / \mathrm{kg}$ bd. wt.

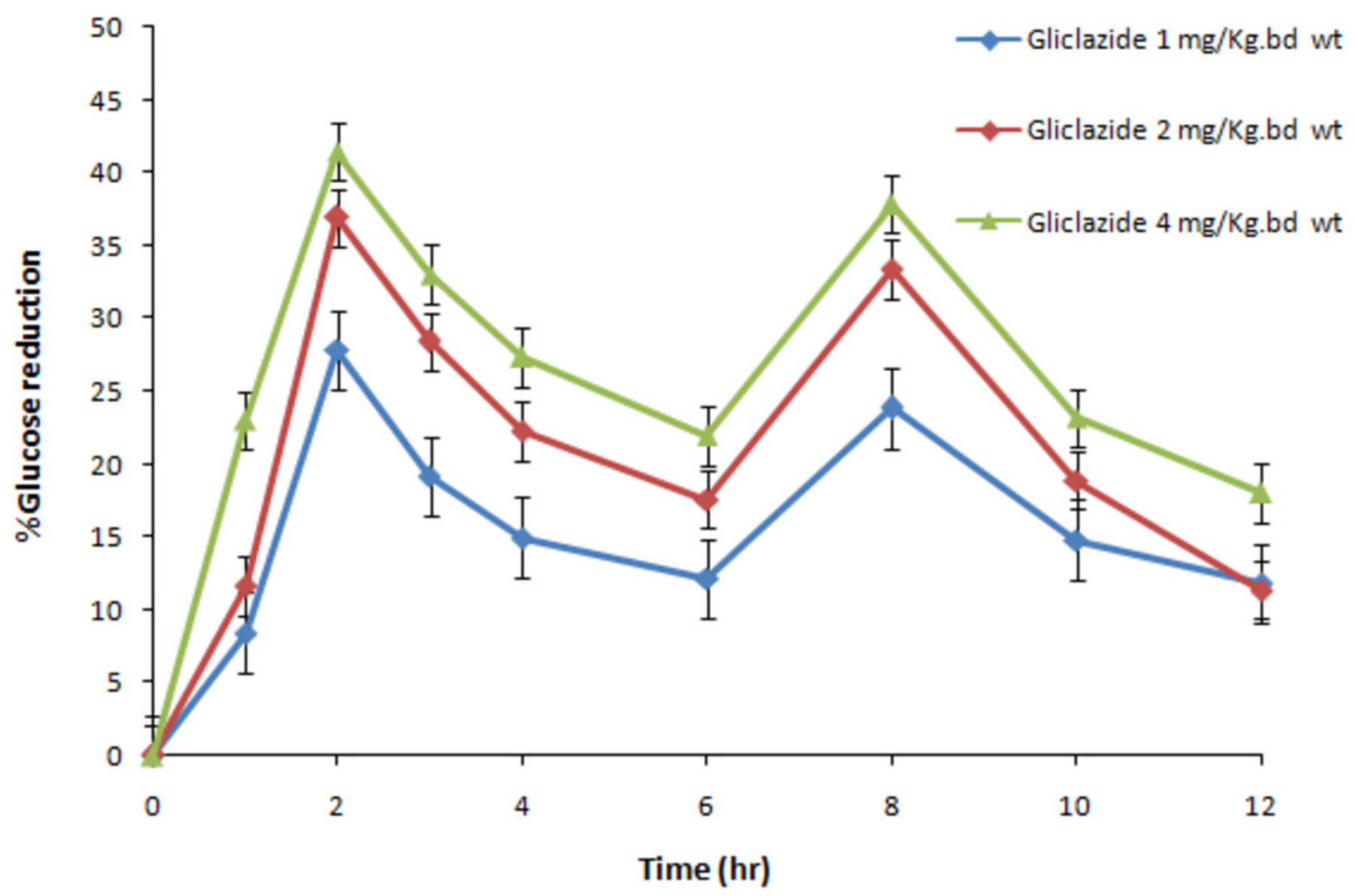




\section{Figure 3}

Mean insulin levels of gliclazide treatment in presence and absence of aprepitant in rat and rabbits $(n=6)$

Blue $=$ Gliclazide treatment; Green $=$ Single dose of aprepitant + Gliclazide; Pink = Multiple dose of aprepitant + Gliclazide; Yellow $=$ Aprepitant treatment ${ }^{*} \mathrm{P}<0.001$ compared to gliclazide group; $* * P<0.01$ compared to gliclazide group; $* \mathrm{P}<0.05$ compared to gliclazide group;

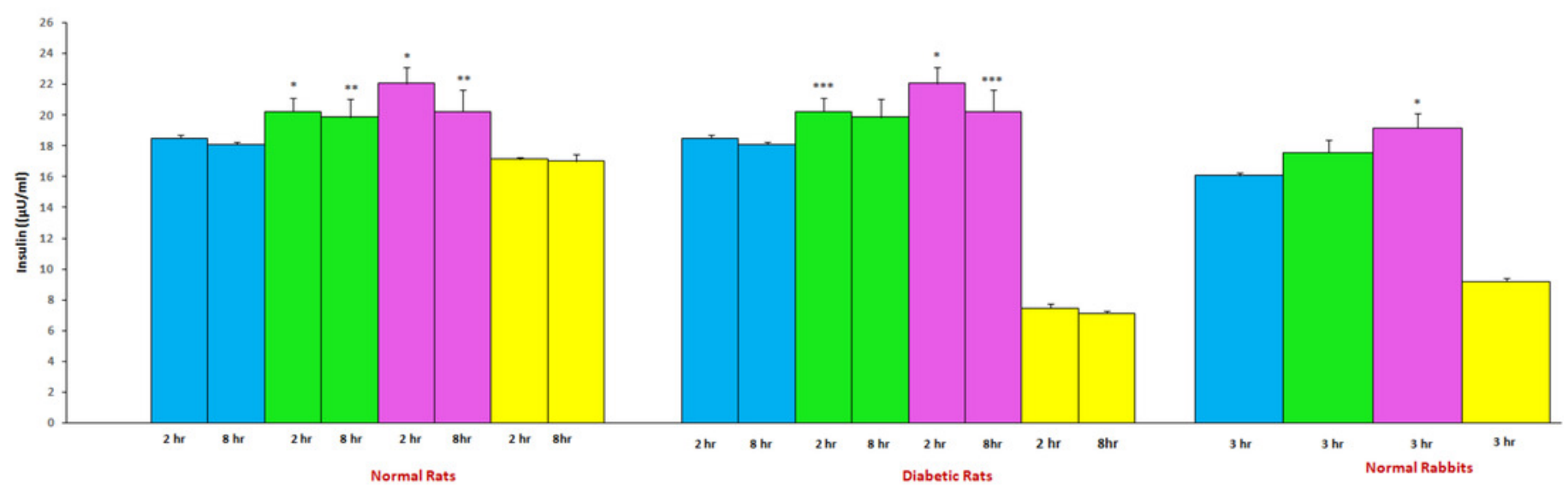




\section{Figure 4}

Mean serum gliclazide concentration-time profile of gliclazide in presence and absence of aprepitant in rabbits $(n=6)$

Blue $=$ Gliclazide treatment; Pink $=$ Single dose of aprepitant + Gliclazide; Green $=$ Multiple dose of gliclazide + Gliclazide

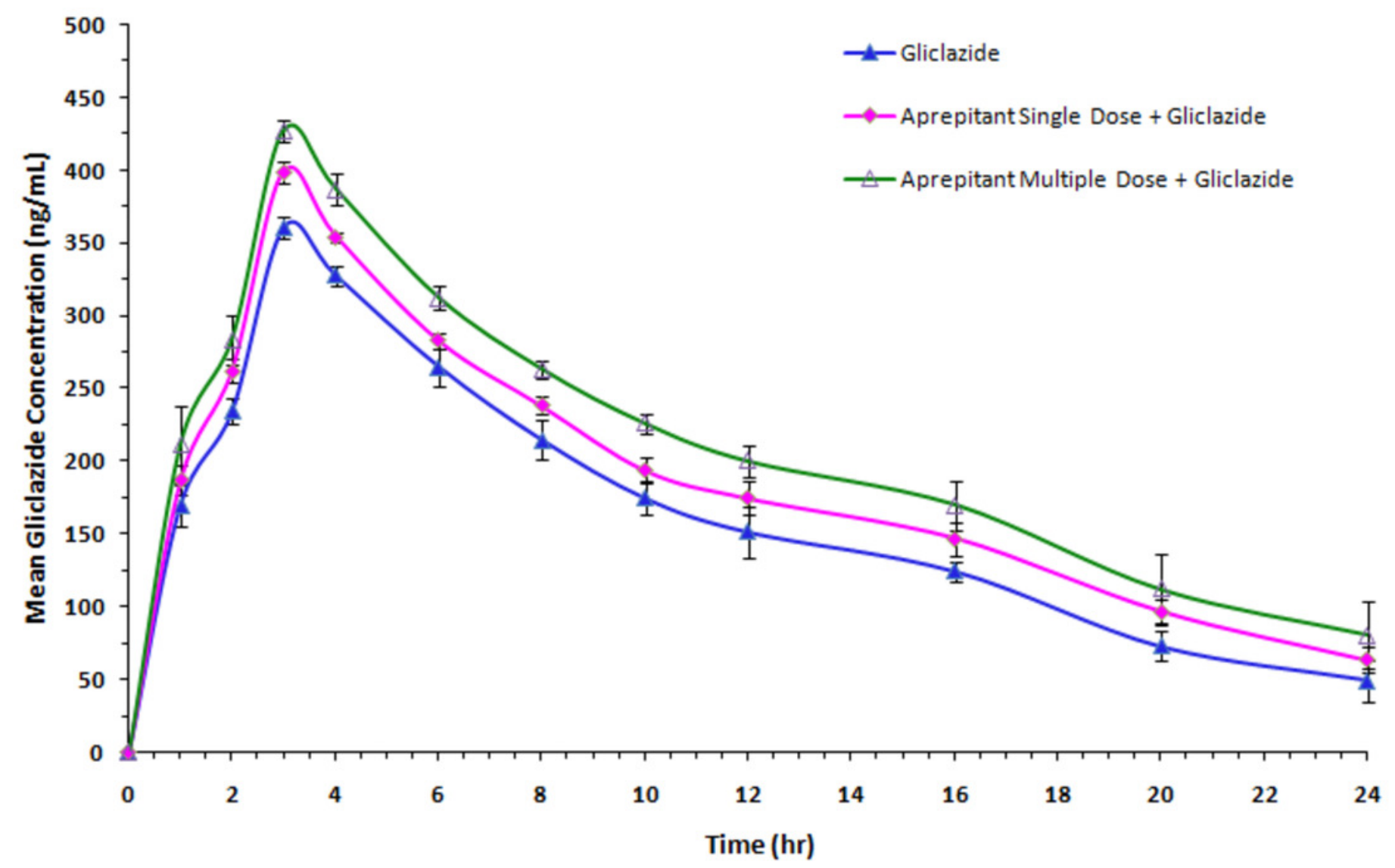

